\section{Commentary: BEEP marks the spot: Novel audiovisual system for localization of lung nodules with radiofrequency identification tagging}

\author{
Alejandro Bribriesco, MD
}

Minimally invasive thoracic surgery (MIS) limits the ability of surgeons to detect pulmonary nodules (PNs) that are small, deep to the pleural surface, and/or part solid. Clinical judgment coupled with knowledge of technology has led to advances in PN targeting. The goal is to maintain a thoracoscopic approach while ensuring that the lesion is identified and then excised, with appropriate margins and minimum parenchyma sacrificed. These tenets maintain equipoise with respect to the risks and benefits of surgery versus other options, such as nonsurgical biopsy or radiographic surveillance. In a study of metastatic PNs, Nakashima and colleagues ${ }^{1}$ proposed that localization should be considered if 2 of the following 3 criteria are met: maximum PN diameter $\leq 5 \mathrm{~mm}$; ratio of maximum PN diameter to the minimum distance between the pleura and $\mathrm{PN}<0.5$; and low density of PN on computed tomography (CT) scan (after chemotherapy). A multitude of localization options has emerged using transthoracic or transbronchial placement of markers, including microcoils, fiducials, dyes, and various combinations of markers. ${ }^{2}$

Continued innovation in PN localization has been spurred by necessity and fueled by technology. One

\footnotetext{
From the Section of Thoracic Surgery, Department of Thoracic and Cardiovascular Surgery, Heart Vascular and Thoracic Institute, Cleveland Clinic, Cleveland, Ohio. Disclosures: The author reported no conflicts of interest.

The Journal policy requires editors and reviewers to disclose conflicts of interest and to decline handling or reviewing manuscripts for which they may have a conflict of interest. The editors and reviewers of this article have no conflicts of interest.

Received for publication Nov 1, 2020; revisions received Nov 1, 2020; accepted for publication Nov 6, 2020; available ahead of print Nov 16, 2020.

Address for reprints: Alejandro Bribriesco, MD, Section of Thoracic Surgery, Department of Thoracic and Cardiovascular Surgery Heart, Vascular and Thoracic Institute, Cleveland Clinic, 9500 Euclid Ave/Mailstop J4-1, Cleveland, OH 44195 (E-mail: bribria@ccf.org).

JTCVS Techniques 2020;4:307-8

2666-2507

Copyright (C) 2020 The Authors. Published by Elsevier Inc. on behalf of The American Association for Thoracic Surgery. This is an open access article under the CC BY-NCND license (http://creativecommons.org/licenses/by-nc-nd/4.0/).

https://doi.org/10.1016/j.xjtc.2020.11.001
}

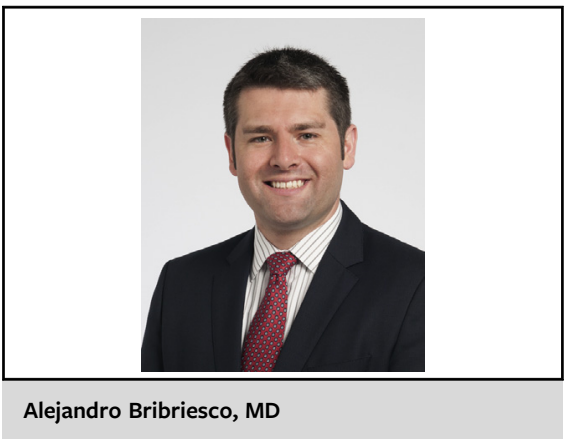

\author{
CENTRAL MESSAGE \\ Transbronchial radiofrequency \\ identification tagging is a novel \\ technology for audiovisual local- \\ ization of small, part-solid pul- \\ monary nodules to facilitate \\ minimally invasive resection.
}

example is electromagnetic navigational bronchoscopy (ENB) deployment of localization material. The use of ENB to assist robotic MIS was first reported by Bolton and colleagues in $2014,{ }^{3}$ with subsequent groups presenting refined techniques for targeting of PNs by ENB injection of dye. ${ }^{4-6}$ Using this combination of intraoperative ENB dye and robotic resection, Geraci and colleagues ${ }^{6}$ and Abbas and colleagues ${ }^{5}$ reported success rates of $86 \%$ and $98.1 \%$, respectively. However, both groups reported modifying their techniques during the course of their studies to mitigate observed limitations with initial methods of dye injection. Geraci and colleagues placed a suture to mark the PN before indocyanine green (ICG) parenchymal diffusion, whereas Abbas and colleagues added radiopaque dye (Isovue) and ICG to improve on methylene blue alone. This highlights the continued opportunity and need for innovation in PN localization.

In this issue of JTCVS Techniques, Sato and colleagues ${ }^{7}$ present a new option for targeting PNs for MIS resection. This inventive case report demonstrates the proof-ofconcept, translational application of a novel radiofrequency identification (RFID) tagging system initially developed in a preclinical canine model. The RFID tag is inserted via a bronchoscope (without ENB) in a hybrid operating room with cone-beam CT scan and intraoperative fluoroscopy. The accompanying video demonstrates successful MIS resection of a 7-mm subsolid PN guided by the RFID audiovisual interface. Notably, the pleural space was hostile with dense adhesions and visceral pleural effacement. 
Fortuitously, this highlights how RFID could be advantageous in certain situations where direct visualization is limited. Further applications of this RFID system have been previously demonstrated during preclinical development with the use of multiple unique RFID tags to guide segmentectomy and sub-segmentectomy. ${ }^{8,9}$ Delivery via ENB is mentioned as an intuitive future modification.

As with any preliminary report of a new technology, there are inherent limitations of as-yet undetermined factors, such as cost and comparative efficacy versus current techniques. Regardless, the authors should be congratulated for this first-in-human report of a new, clinically relevant tool that will potentially add to the armamentarium of the modern thoracic surgeon.

\section{References}

1. Nakashima S, Watanabe A, Obama T, Yamada G, Takahashi H, Higami T. Need for preoperative computed tomography-guided localization in video-assisted thoracoscopic surgery pulmonary resections of metastatic pulmonary nodules. Ann Thorac Surg. 2010;89:212-8.
2. Velasquez R, Martin A, Abu Hishmeh M, DeLorenzo L, Dhillon SS, Harris K. Placement of markers to assist minimally invasive resection of peripheral lung lesions. Ann Transl Med. 2019;7:360.

3. Bolton WD, Howe H III, Stephenson JE. The utility of electromagnetic navigational bronchoscopy as a localization tool for robotic resection of small pulmonary nodules. Ann Thorac Surg. 2014;98:471-5; discussion 475-6.

4. Anayama T, Qiu J, Chan H, Nakajima T, Weersink R, Daly M, et al. Localization of pulmonary nodules using navigation bronchoscope and a near-infrared fluorescence thoracoscope. Ann Thorac Surg. 2015;99:224-30.

5. Abbas A, Kadakia S, Ambur V, Muro K, Kaiser L. Intraoperative electromagnetic navigational bronchoscopic localization of small, deep, or subsolid pulmonary nodules. J Thorac Cardiovasc Surg. 2017;153:1581-90.

6. Geraci TC, Ferrari-Light D, Kent A, Michaud G, Zervos M, Pass HI, et al. Technique, outcomes with navigational bronchoscopy using indocyanine green for robotic segmentectomy. Ann Thorac Surg. 2019;108:363-9.

7. Sato T, Yutaka Y, Nakamura T, Date H. First clinical application of radiofrequency identification (RFID) marking system-precise localization of a small lung nodule. J Thorac Cardiovasc Surg Tech. 2020;4:301-4.

8. Sato M, Kobayashi M, Kojima F, Tanaka F, Yanagiya M, Kosaka S, et al. Effect of virtual-assisted lung mapping in acquisition of surgical margins in sublobar lung resection. J Thorac Cardiovasc Surg. 2018;156:1691-701.e5.

9. Yutaka Y, Sato T, Matsushita K, Aiba H, Muranishi Y, Sakaguchi Y, et al. Three-dimensional navigation for thoracoscopic sublobar resection using a novel wireless marking system. Semin Thorac Cardiovasc Surg. 2018;30: $230-7$. 